\title{
COMPORTAMENTO DE CULTIVARES DE MELOEIRO E MELANCIA INOCULADOS COM Acremonium cucurbitacearum E Monosporascus cannonballus
}

\author{
RUI SALES JÚNIOR ${ }^{1 *}$, ANTONIO VICENT ${ }^{2}$, JOSEP ARMENGOL ${ }^{2}$, JOSÉ GARCÍA-JIMÉNEZ ${ }^{2}$ \\ \& RÔMULO F. KOBORI ${ }^{3}$
}

'Escola Superior de Agricultura de Mossoró, Cx. Postal 137, CEP 59.625-900, Mossoró, RN, e-mail: jrrui@ @otmail.com; ${ }^{2}$ Universidad Politécnica de Valencia, E.T.S.I.Agrônomos, Camino de Vera s/n, 46020, Valencia, Espanha;

${ }^{3}$ AGROFLORA/SAKATA, Cx. Postal 427, CEP 12906-840, Bragança Paulista-SP

(Aceito para correspondência em 22/02/2002)

Autor para correspondência: Rui Sales Júnior

SALES JR, R., VICENT, A., ARMENGOL, J., GARCÍA-JIMÉNEZ, J. \& KOBORI, R.F. Comportamento de cultivares de meloeiro e melancia inoculados com Acremonium cucurbitacearum e Monosporascus cannonballus. Fitopatologia Brasileira 27:206-210. 2002.

\section{RESUMO}

O colapso em cucurbitáceas é uma síndrome complexa na qual podem estar envolvidos numerosos agentes fitopatógenos, sendo bastante freqüente o ataque associado de vários deles. No presente trabalho é apresentado o comportamento de 19 cultivares de meloeiro (Cucumis melo) e duas de melancia (Citrullus lanatus), cultivadas no Brasil, frente a Acremonium cucurbitacearum e Monosporascus cannonballus, dois dos patógenos fúngicos associados a esta síndrome em diversos países. Todas as cultivares de meloiro e melancia mostraram-se susceptíveis a estes patógenos, obtendo-se valores de 2,2 até 4,4 de índice geral de doença (IGD) para as cultivares de melão inoculadas com ambos os fungos e 2,4 até 2,5 para as cultivares de melancia inoculadas com $A$. cucurbitacearum. As cultivares de melancia mostraram resistência na combinação com $M$. cannonballus. A conveniência de efetuar estudos com outras cultivares utilizando a metodologia desenvolvida neste trabalho é discutida.

Palavras-chave adicionais: Vine decline, patogenicidade, inoculação, fungos de solo, patógenos de raízes.

\section{ABSTRACT \\ Behaviour of melon and watermelon cultivars inoculated with Acremonium cucurbitacearum and Monosporascus cannonballus}

Vine decline or collapse on cucurbits is a syndrome that can be caused by several phytopathogenic agents and is frequently associated with the attack of several of them. Acremonium cucurbitacearum and Monosporascus cannonballus are two of the main fungal pathogens associated with this syndrome. The pathogenicity of these fungi was evaluated for 19 muskmelon (Cucumis melo) and two watermelon (Citrullus lanatus) cultivars usually cultivated in Brazil. All cultivars tested were highly susceptible to these pathogens except for the combination watermelon- $M$. cannonballus. The importance of continuing the study with other cultivars using the methodology described is discussed.
Nos últimos anos têm sido detectadas, com importância crescente, diversas doenças de solo que afetam o meloeiro (Cucumis melo L.) e a melancia [Citrullus lanatus (Thunb.) Matsum. et Nakai]. Entre as causas que contribuem para o incremento e a severidade destas doenças são citadas várias práticas culturais como: introdução de cultivares suscetíveis, transplante, utilização de plástico (mulch), irrigação por gotejamento, aumento na densidade de plantio, e ausência de rotações de cultivos adequados (Bruton, 1998). Dentre as doenças citadas na literatura, há um grupo que recebe denominações como "vine decline", "sudden wilt", "collapse" ou "sudden death" e que, na bibliografia espanhola, denominase "colapso" ou "morte súbita" (García-Jiménez et al., 1994a).

O "colapso" é uma síndrome complexa que pode apresentar-se associada a numerosos agentes, tanto fungos como bactérias e vírus, ocorrendo, com certa freqüência, o

\footnotetext{
* Bolsista do CNPq
}

ataque conjunto de vários deles (Bruton, 1998). Atualmente dois dos agentes fúngicos mais importantes associados a esta síndrome afetando o meloeiro e a melancia são Acremonium cucurbitacearum Alfaro-García, W. Gams et J. GarciaJiménez, descrito na Espanha (Alfaro-García et al., 1996) e Estados Unidos (Aegerter et al., 2000) e Monosporascus cannonballus Pollack et Uecker na Arábia Saudita, Espanha, Estados Unidos, Honduras, Guatemala, Itália, Israel, Japão, México, Taiwan e Tunísia (Martyn \& Miller, 1996).

$\mathrm{O}$ ataque de $A$. cucurbitacearum em raiz de meloeiro e melancia apresenta uma sintomatologia muito parecida. No início observa-se a presença de um ligeiro pardeamento na zona de inserção raiz-hipocótilo, seguido de morte progressiva das raízes secundárias e terciárias, e posteriormente necrose e suberificação das raízes principais (García-Jiménez, et al., 1989). As infecções com $M$. cannonballus são caracterizadas pela presença de necrose e podridões na raiz principal seguidas da perda de raízes secundárias e terciárias. Nas últimas fases 
da doença nota-se, com freqüência, a presença de peritécios do fungo infiltrados nas raízes afetadas.

Dada a crescente importância deste complexo de doenças no mundo, até o momento não relatado no Brasil, principalmente nas regiões produtoras de melão como o nordeste, o presente trabalho teve como objetivo estudar o comportamento de diferentes cultivares de meloeiro e melancia cultivados no Brasil frente a ambos patógenos.

O presente trabalho foi realizado em casa de vegetação (estufa) na Universidad Politécnica de Valência - Valência Espanha.

\section{Isolados fúngicos e métodos de inoculação}

Utilizaram-se dois isolados fúngicos de procedência espanhola: um de A. cucurbitacearum: A-419 (CBS 525.93, cepa de referência) isolado de meloeiro e outro de $M$. cannonballus: (M1) cepa de abóbora (Cucurbita moschata L.), e que em ensaios prévios mostrou-se patogênico ao meloeiro (Sales, 1999).

O inóculo foi produzido em substrato artificial de areiaflocos de aveia na proporção 1.000:91,5 (v/p), segundo metodologia desenvolvida por Armengol et al. (1998).

Neste estudo foram utilizadas 19 cultivares de meloeiro e duas de melancia de distintos tipos cultivados no Brasil (Tabela 1).

Para a inoculação foram preparados recipientes de 16 $\mathrm{cm}$ de diâmetro com uma mistura em volume de 1:1:1 de terra, turfa e areia, previamente esterilizada em autoclave a $120{ }^{\circ} \mathrm{C}$ durante $1 \mathrm{~h}$. Nesses recipientes foi adicionada uma concentração de inóculo de $5 \times 10^{4}$ u.f.c./g de solo para $A$. cucurbitacearum (Armengol et al, 1999) e 20 u.f.c./g de solo para o isolado de M. cannonballus (Bruton et al, 1995).

As sementes das cultivares de meloeiro e melancia foram desinfetadas superficialmente com hipoclorito sódico (1,5\% de cloro ativo, durante $1 \mathrm{~min}$ ) e, uma vez prégerminadas, transplantadas quatro plantas por recipiente. Após a germinação, foram mantidas somente duas plantas por recipiente. Foram utilizados três recipientes de cada cultivar para cada um dos isolados fúngicos e três recipientes com terra estéril também com duas plantas para cada cultivar

TABELA 1 - Relação de cultivares de meloeiro (Cucumis melo) e melancia (Citrullus lanatus) cultivadas no Brasil e utilizadas neste ensaio

\begin{tabular}{|c|c|c|}
\hline Espécie & Tipo & Cultivar \\
\hline \multirow[t]{2}{*}{$\begin{array}{l}\text { Cucumis melo var. } \\
\text { cantalupensis }\end{array}$} & Cantalupe & $\begin{array}{l}\text { AF-581-4-OP, AF-515-OP, AF-143-OP, } \\
\text { AF-105-OP, AF-67-OP, AF-63-OP, } \\
\text { AF-1701-F1 }\end{array}$ \\
\hline & Charentais & AF-2147-F1 \\
\hline C. melo var. inodorus & Yellow & $\begin{array}{l}\text { AF-1498-F1, AF-682-F1, AF-646-F1, } \\
\text { AF-1805-F1 }\end{array}$ \\
\hline $\begin{array}{l}\text { C. melo var. } \\
\text { saccharinus }\end{array}$ & Piel de Sapo & PS-1430, AF1649-F1, Manchado F1 \\
\hline Outros & & $\begin{array}{l}\text { Orange Flesh, Honey Dew, Yellow King, } \\
\text { AF-692 }\end{array}$ \\
\hline Citrullus lanatus & & cv. Charleston Gray, cv. Crimson Sweet \\
\hline
\end{tabular}

como controle testemunha sem inoculação.

Os recipientes foram levados para uma estufa controlada em condições ambientais de $25-30^{\circ} \mathrm{C}$ e com alta umidade relativa. $\mathrm{O}$ ensaio foi conduzido durante dois meses, sendo realizado várias avaliações durante este período.

\section{Avaliação da sanidade das plantas}

Após o período de 60 dias, as plantas foram arrancadas cuidadosamente e as raízes lavadas em água corrente para eliminar os restos de terra aderidos. Em seguida, foi avaliada a sanidade, numa escala de notas de 1 a 5, para o hipocótilo, raiz principal e raízes secundárias e terciárias (Armengol et al., 1998).

Uma outra variável utilizada foi o índice geral de doença (IGD) com média dos valores obtidos para o colo, raiz primária e raízes secundárias e terciárias.

Após a avaliação visual, procedeu-se ao reisolamento dos fungos das raízes em meio de cultura de BDA + 500 ppm de estreptomicina. De cada uma das seis plantas inoculadas de cada cultivar e isolado fúngico, foram realizados cinco pontos de isolamento, preferencialmente das zonas afetadas.

As placas foram incubadas durante período de três a cinco dias a $25-27^{\circ} \mathrm{C}$, dos quais se avaliou a freqüência de reisolamento de $A$. cucurbitacearum e $M$. cannonballus.

De acordo com os resultados de patogenicidade e reisolamento de A. cucurbitacearum (Tabela 2) e M. cannonballus (Tabela 3). O IGD para as cultivares é apresentado em ordem crescente de susceptibilidade.

As cultivares de meloeiro e melancia estudadas neste trabalho apresentaram uma ampla variação de reações aos dois isolados fúngicos estudados. Convencionalmente se estabeleceu um agrupamento arbitrário para o IGD, sendo as seguintes categorias: $1-1,9=$ resistente; $2-2,9=$ mediamente resistente; 3-3,9 = susceptível; 4- 5 = muito susceptível (Armengol et al., 1998; Armengol et al., 1999).

No caso da inoculação com $A$. cucurbitacearum (Tabela 2), o IGD das cultivares de meloeiro variou desde 2,2 até 4,4 obtendo-se uma graduação desde cultivares mediamente resistentes (AF-105-OP, AF-1805-F1, AF-581-4-OP, AF515-OP, Orange Flesh, AF-143-OP, AF-1649-F1), suscetíveis (AF-1701-F1, AF-646-F1, Honey Dew, Yellow King, AF-682F1, AF-2147-F1, AF-1498-F1, AF-67-OP, Manchado F1) até muito susceptíveis (AF-63-OP, PS-1430, AF-692).

Acremonium cucurbitacearum foi reisolado das raízes de todas as cultivares de meloeiro utilizadas, obtendo-se valores significativos, com exceção da cultivar AF-581-4-OP, para a qual se obteve uma porcentagem de reisolamento muito baixa $(3,3 \%)$.

Para a inoculação com M. cannonballus (Tabela 3), o IGD variou também de 2,2 até 4,4 obtendo-se, também, uma graduação desde cultivares medianamente resistentes (AF581-4-OP, AF-515-OP, AF-105-OP, AF-67-OP, AF-646-F1, AF-2147-F1), susceptíveis (AF-1805-F1, AF-682-F1, AF1701-F1, AF-63-OP, Orange Flesh, Manchado F1, AF-1649F1, Honey Dew, AF-1498-F1, AF-143-OP, Yellow King) até muito susceptíveis (PS-1430, AF-692). 
TABELA 2 - Patogenicidade em meloeiro (Cucumis melo) e melancia (Citrullus lanatus) e reisolamento de Acremonium cucurbitacearum

\begin{tabular}{|c|c|c|c|c|c|c|c|}
\hline \multirow[b]{2}{*}{ Espécie } & \multirow[b]{2}{*}{ Cultivar $^{a}$} & \multicolumn{3}{|c|}{ Nível de dano $^{\text {b }}$} & \multicolumn{2}{|c|}{ IGD $^{c}$} & \multirow{2}{*}{$\begin{array}{c}\text { Isolamento } \\
(\%)^{\mathrm{e}}\end{array}$} \\
\hline & & Hipocótilo & $\begin{array}{c}\text { Raiz } \\
\text { primaria }\end{array}$ & $\begin{array}{c}\text { Raiz } \\
\text { secundária }\end{array}$ & Media & Categoria $^{d}$ & \\
\hline \multirow[t]{19}{*}{ Cucumis melo } & AF-105-OP & 1,7 & 2,4 & 2,4 & 2,2 & 1 & 40 \\
\hline & AF-1805-F1 & 1,7 & 2,2 & 2,8 & 2,2 & 1 & 77 \\
\hline & AF-581-4-OP & 1,8 & 3,0 & 3,0 & 2,6 & 3 & 3,3 \\
\hline & AF-515-OP & 2,5 & 2,3 & 3,2 & 2,7 & 4 & 67 \\
\hline & Orange Flesh & 3,0 & 2,7 & 2,8 & 2,8 & 5 & 80 \\
\hline & AF-143-OP & 2,8 & 2,8 & 3,0 & 2,9 & 6 & 28 \\
\hline & AF-1649-F1 & 2,0 & 2,7 & 4,0 & 2,9 & 6 & 97 \\
\hline & AF-1701-F1 & 3,3 & 3,0 & 3,3 & 3,2 & 8 & 50 \\
\hline & AF-646-F1 & 3,0 & 3,0 & 3,7 & 3,2 & 8 & 80 \\
\hline & Honey Dew & 2,8 & 2,8 & 4,0 & 3,2 & 8 & 60 \\
\hline & Yellow King & 2,3 & 3,0 & 4,2 & 3,2 & 8 & 24 \\
\hline & AF-682-F1 & 2,5 & 3,2 & 4,2 & 3,3 & 12 & 30 \\
\hline & AF-2147-F1 & 3,0 & 3,0 & 3,8 & 3,3 & 12 & 90 \\
\hline & AF-1498-F1 & 3,4 & 3,0 & 3,8 & 3,4 & 14 & 73 \\
\hline & AF-67-OP & 4,0 & 3,0 & 4,0 & 3,7 & 15 & 50 \\
\hline & Manchado F1 & 3,7 & 3,1 & 4,3 & 3,7 & 15 & 57 \\
\hline & AF-63-OP & 4,0 & 3,4 & 4,6 & 4,0 & 17 & 93 \\
\hline & Piel de Sapo PS-1430 & 4,2 & 4,8 & 4,2 & 4,4 & 18 & 90 \\
\hline & AF-692 & 3,7 & 5,0 & 4,5 & 4,4 & 18 & 36 \\
\hline \multirow[t]{2}{*}{ Citrullus lanatus } & Charleston Gray & 2,4 & 2,0 & 2,9 & 2,4 & 1 & 78 \\
\hline & Crimson Sweet & 2,6 & 2,0 & 2,8 & 2,5 & 2 & 88 \\
\hline
\end{tabular}

${ }^{\mathrm{a}} \mathrm{AF}-105, \mathrm{AF}-581-4, \mathrm{AF}-515, \mathrm{AF}-143, \mathrm{AF}-67, \mathrm{AF}-2147$ e AF- 63= C.m. cantaloupensis; AF- 1805, AF- 1649, AF- 1701, AF- 646, AF- 682,

AF- 1498, AF-692, Yellow King, Manchado, Piel de Sapo PS- 143, Orange Flesh e Honey Dew =C. m. inodorus

'Valores médios de reações do hospedeiro a infecção avaliados em uma escala de 1 (sadias) a 5 (muito afetadas).

'IGD, Índice geral de doença; os valores são as medias dos níveis de danos em hipocótilo, raiz primária e raízes secundárias.

'Ordem de susceptibilidade crescente a A. cucurbitacearum; plantas com a mesma média apresentam categoria idêntica.

ePorcentagem de 30 fragmentos de raiz dos quais $A$. cucurbitacearum foi isolado.

A inoculação das cultivares de melancia com $A$. cucurbitacearum apresentou valores de IGD de 2,4 e 2,5 (Charleston Gray e Crimson Sweet respectivamente) estando dentro dos valores das plantas medianamente resistentes. Neste caso o fungo foi reisolado das raízes com valores acima de $75 \%$ em ambos casos (Tabela 2).

Por outro lado, as cultivares de melancia mostraram nível de resistência para $M$. cannonballus com valores de IGD= 1,1 e 1,3, respectivamente. M. cannonballus foi reisolado das raízes de ambas cultivares apresentando valores de $42 \%$ (Charleston Gray) e 20\% (Crimson Sweet).

Garcia-Jiménez et al. (1994b), estudando o comportamento de 55 cultivares de meloeiro em campos distintos naturalmente infestados por $A$. cucurbitacerum, verificaram que todas as cultivares se comportaram como suscetíveis ao colapso apresentando valores de danos em raízes, numa escala de 0 (raiz sadia) até 3 (muito afetada), compreendidos entre 2 e 3 para quase todas as cultivares testadas. Paralelamente, num estudo em recipientes também com solo naturalmente infestado, Armengol (1997) testou um total de 88 cultivares comerciais de meloeiro e não encontrou resistência frente ao colapso em nenhuma delas. Os danos observados nas raízes das cultivares estudadas foram similares aos obtidos por Armengol et al. (1998).

Wolff (1995), em um estudo de patogenicidade realizado em recipientes com 130 cultivares de meloeiro, demons- trou que 108 deles eram moderados ou altamente suscetíveis ao ataque de $M$. cannonballus.

Os resultados obtidos neste trabalho mostram claramente que as cultivares de meloeiro foram bastante suscetíveis a ambos os patógenos, com exceção da cultivar AF - 581-4 OP para o caso de A. cucurbitacearum e também para as cultivares de melancia frente a inoculação $\operatorname{com} M$. cannonballus. Esses resultados corroboram com os obtidos por Armengol et al. (1998) que demonstraram que a patogenicidade de $M$. cannonballus e A. cucurbitacearum em cucurbitáceas é elevada, sendo os mais susceptíveis o meloeiro e a melancia.

É interessante relatar que, na Espanha, os prejuízos em campo de produção comercial causados por A. cucurbitacearum em melancia não foram, até o momento, importantes. Armengol et al. (1998) indicam que a enxertia de melancia sobre híbridos de abóbora controla com eficiência o colapso causado por $A$. cucurbitacearum, já que a abóbora é uma das espécies de cucurbitáceas que apresenta maior resistência a este fungo.

Embora o trabalho tenha sido realizado com número limitado de cultivares de meloeiro e melancia, a importância destes patógenos em áreas de produção de cucurbitáceas em outros países é grande. Tendo em vista a não ocorrência, até o momento, destes patógenos no Brasil, trabalhos de avaliação de genótipos ou híbridos de meloeiros e melancia são 
Comportamento de cultivares de melão e melancia inoculadas com Acremonium...

TABELA 3 - Patogenicidade em meloeiro (Cucumis melo) e melancia (Citrullus lanatus) e reisolamento de Monosporascus cannonballus

\begin{tabular}{|c|c|c|c|c|c|c|c|}
\hline \multirow[b]{2}{*}{ Espécie } & \multirow[b]{2}{*}{ Cultivar ${ }^{a}$} & \multicolumn{3}{|c|}{ Nível de dano b $^{b}$} & \multicolumn{2}{|c|}{ IGD $^{\mathrm{c}}$} & \multirow{2}{*}{$\begin{array}{c}\text { Isolamento } \\
(\%)^{\mathrm{e}}\end{array}$} \\
\hline & & Hipocótilo & $\begin{array}{c}\text { Raiz } \\
\text { primaria }\end{array}$ & $\begin{array}{c}\text { Raiz } \\
\text { secundária }\end{array}$ & Media & Categoria $^{d}$ & \\
\hline \multirow{14}{*}{ Cucumis melo } & AF-581-4-OP & 2,3 & 2,3 & 2,0 & 2,2 & 1 & 80 \\
\hline & AF-515-OP & 1,7 & 2,5 & 2,3 & 2,2 & 1 & 90 \\
\hline & AF-105-OP & 1,8 & 3,3 & 2,8 & 2,6 & 3 & 100 \\
\hline & AF-67-OP & 2,0 & 3,0 & 3,0 & 2,7 & 4 & 60 \\
\hline & AF-2147-F1 & 2,5 & 2,5 & 3,3 & 2,8 & 5 & 80 \\
\hline & AF-1805-F1 & 2,6 & 3,6 & 2,8 & 3,0 & 7 & 92 \\
\hline & AF-682-F1 & 2,7 & 3,2 & 3,3 & 3,1 & 8 & 100 \\
\hline & AF-1701-F1 & 3,3 & 3,0 & 3,3 & 3,2 & 9 & 93 \\
\hline & AF-63-OP & 3,2 & 3,2 & 3,2 & 3,2 & 9 & 88 \\
\hline & AF-1498-F1 & 3,0 & 4,2 & 3,5 & 3,6 & 13 & 90 \\
\hline & AF-143-OP & 3,4 & 4,4 & 3,6 & 3,8 & 15 & 77 \\
\hline & Yellow King & 3,6 & 4,0 & 3,8 & 3,8 & 15 & 80 \\
\hline & Piel de Sapo PS-1430 & 3,4 & 4,8 & 4,2 & 4,1 & 17 & 92 \\
\hline & AF-692 & 3,7 & 5,0 & 4,5 & 4,4 & 17 & 83 \\
\hline \multirow[t]{2}{*}{ Citrullus lanatus } & Charleston Gray & 0,8 & 1,4 & 1,1 & 1,1 & 1 & 42 \\
\hline & Crimson Sweet & 1,1 & 1,2 & 1,3 & 1,3 & 2 & 20 \\
\hline
\end{tabular}

aAF- 105, AF- 581-4, AF-515, AF- 143, AF- 67, AF- 2147 e AF- 63= C.m. cantaloupensis; AF- 1805, AF- 1649, AF- 1701, AF- 646, AF- 682, AF- 1498, AF-692, Yellow King, Manchado, Piel de Sapo PS- 143, Orange Flesh e Honey Dew = C. m. inodorus

bValores médios de reações do hospedeiro a infecção avaliados em uma escala de 1 (sadias) a 5 (muito afetadas).

'IGD, Índice geral de doença; os valores são as medias dos níveis de danos em hipocótilo, raiz primária e raízes secundárias.

${ }^{\mathrm{d}}$ Ordem de susceptibilidade crescente a $A$. cucurbitacearum; plantas com a mesma média apresentam categoria idêntica.

ePorcentagem de 30 fragmentos de raiz dos quais $A$. cucurbitacearum foi isolado.

necessários para orientar o controle pelo uso de cultivares resistentes numa futura ocorrência destes fungos no Brasil.

\section{AGRADECIMENTOS}

O presente trabalho foi realizado com o suporte financeiro da Comissão Interministerial de Ciência e Tecnologia (CICYT) da Espanha através do Projeto de Investigação AGF97-1208-C03-01. Gostaríamos de expressar nosso agradecimento a AGROFLORA, em nome do Dr. Rômulo F. Kobori pelo fornecimento de sementes de melão de diferentes tipos para serem testadas neste trabalho.

\section{REFERÊNCIAS BIBLIOGRÁFICAS}

AEGERTER, B.J., GORDON, T.R. \& DAVIS R.M. Occurrence and pathogenicity of fungi associated with melon root rot and vine decline in California. Plant Disease 84:224-230. 2000.

ALFARO-GARCÍA, A., ARMENGOL, J., BRUTON, B.D., GAMS, W., GARCÍA-JIMÉNEZ, J. \& MARTÍNEZFERRER, G. The taxonomic position of the causal agent of Acremonium collapse of muskmelon. Mycologia 88:804-808. 1996.

ARMENGOL, J. Aspectos patológicos, epidemiológicos y culturales de Acremonium cucurbitacearum Alfaro-García, W. Gams et J. García-Jiménez. (Tese de Doutorado). Valencia: Universidad Politécnica de Valencia "E.T.S.I.A.". 1997.

ARMENGOL, J., SALES, R. \& GARCÍA-JIMÉNEZ, J. Evolución de los daños causados por Acremonium cucurbitacearum en raíz de melón es sus primeros estados de desarrollo. Boletin de Sanidad Vegetal Plagas 25:265-277. 1999.

ARMENGOL, J., SANZ, E., MARTÍNEZ-FERRER, G., SALES, R., BRUTON, B.D. \& GARCÍA-JIMÉNEZ, J. Host range of Acremonium cucurbitacearum, cause of Acremonium collapse of muskmelon. Plant Pathology 47:29-35. 1998.

BRUTON, B.D. Soilborne diseases in Cucurbitaceae: Pathogen virulence and host resistance. In: McCreight, J. (Ed.) CUCURBITACEAE '98. Amer. Soc. of Hort. Sci. Press, Alex., Va, 1998. pp.143-166.

BRUTON, B.D., DAVIS, R.M. \& GORDON, T.R. Occurrence of Acremonium sp. and Monosporascus cannonballus in the major cantaloupe and watermelon growing areas of California. Plant Disease 79:754. 1995. (Note).

GARCÍA-JIMÉNEZ, J., VELÁZQUEZ, M.T. \& ALFAROGARCÍA, A. Secuencia de síntomas en el colapso del melón. Boletín de Sanidad Vegetal Plagas 15:333-342. 1989.

GARCÍA-JIMÉNEZ, J., VELÁZQUEZ, M.T., JORDÁ, C. \& ALFARO-GARCÍA, A. Acremonium species as the causal agent of muskmelon collapse in Spain. Plant Disease 78:416419. 1994a.

GARCÍA-JIMÉNEZ, J., ARMENGOL, J. \& MARTÍNEZFERRER, G. Resistencia y comportamiento en campo de diversos cultivares de melón crecidos en suelo infestado naturalmente con Acremonium sp. Investigación Agraria. Producción y Protección Vegetal 2:263-274. 1994b.

MARTYN, R.D. \& MILLER, M.E. Monosporascus root rot and vine decline: An emerging disease of melon worldwide. Plant Disease 80:716-725. 1996. 


\section{R. Sales Júnior et al.}

SALES, R. Secuencia del ataque de patógenos fúngicos a raíz de melón. Histopatología de la infección por Acremonium cucurbitacearum Alfaro-García, W. Gams et J. GarcíaJiménez. (Tese de Doutorado). Espanha. Universidad Politécnica de Valencia. 1999.
WOLFF, D.W. Evaluation of melon germplasm for resistance to Monosporascus root rot/vine decline symptom expression in melon (Cucumis melo L.). In: Proceedings, VIth Eucarpia meeting on cucurbit genetics and breeding. Málaga, Espanha. 1995. pp.224-228. 